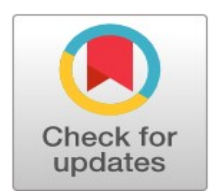

\title{
A frontier in organizational and business process innovation in service management through lean six sigma Kaizen project implementation
}

\author{
Daniel Dasig Jr *
}

College of Computer Science, School of Continuing Professional Education, University of Makati, Makati, Philippines

\author{
Keywords \\ Kaizen project \\ Lean principle \\ Innovation management \\ Process innovation \\ Business performance
}

Received: 19 July 2017

Accepted: 11 September 2017

Published: 4 December 2017

\begin{abstract}
The rudiments and repercussions of the transformative global economy have reshaped the Service Management industry and other developed economies. Business process innovation using Lean Six Sigma (LSS) methodology has long been considered to improve service quality, process efficiency, and organizational performance by deploying Kaizen projects. This paper presents the business process innovation using Define, Measure, Analyze, Improve, and Control (DMAIC) methodology. The results show that the Kaizen Project positively impacted the company's productivity and support efficiency and exceeded Service Level Agreement (SLA). The researcher recommends that the organization should continuously embark on process improvement, document lessons learned, share best practices, and champion LSS projects on larger scale and support operational units in institutionalizing the same innovation. Further studies could be done on the basis of how one-time scheme process betters the quality of the service or product by using other framework and process improvement methodology.
\end{abstract}

(c) 2017 The Author(s). Published by TAF Publishing.

\section{INTRODUCTION}

The ramification of today's businesses encompassed the transformative global economy Dasig Jr (2014) where information system and the rudiments of business innovation have widely been instigated. In the sectors of the economy, the service industry organizations or the tertiary sector in the economic theory confronted many challenges to achieving organizational and operational excellence and providing quality service. Service industry as a dominant economic sector Zurich (2017) has transformed the commercial world and business models in the developed economies. There had been a shift from the conformist scientific management Grönroos (1994) to service management in order to sustain the business competitive advantage Dasig Jr
(2014) and champion the delivery of service value to the customers. The competitive age of service industry catapulted service manager and service provider to entrench lean and system thinking in the mainstream of management and decision-making. Gronroos (1990) posited that methodical and technical solution that has been embedded into the service or goods does not provide a guaranteed placement in the competitive and emerging industry. Gummesson (1994) opined that service management must deliberately-broaden service rapports from both service industry practitioner and the scholars perspective and employ a service framework to forge strategic thinking stamped in services Kellogg \& Nie (1995) being provided. Amongst the service management framework that can be

\footnotetext{
* Corresponding author: Daniel Dasig Jr

†Email: dhuniel2006@yahoo.com
} 
etched in the service catalogues is the IT Service Management, process innovation using LSS methodologies (Ayuningrat, Noermijati \& Hadiwidjojo, 2016; Dasig Jr \& Gatpandan; 2013).

\section{Service and SLM}

A product is generally anything which is offered to a market in order to satisfy the customers' want or need. A service in a business note is another type of product provided by the service industry to the general population or business firms (Dasig Jr, 2014; Jakobsson \& Rosenberg, 2007; Kuo \& Chen, 2015) such as information technology services, telecommunication, schools, financial institutions, and restaurants and other service providers in capacities. Service business is a commercial enterprise that generates revenue and delivers intangible product such as accounting, banking, consulting, education and insurance, retail, transport, distribution, and food services. The wave of Business Process Outsourcing (BPO) and Information Technology Outsourcing (ITO) has bent the web-enabled and service-oriented architectures. In the ITO and BPO, process streamlining and technology optimization were backed through the adaptation of global best practices and even required its human capital to challenge the global certifications. Amongst the global best practices for internal quality management system are the Information Te chnology Infrastructure Library (ITIL) and Information Technology Service Management (ITSM)-ISO 2000 as the framework for service management. In these contexts, information technology is one of the enablers in the service delivery. SLM is employed to align the service strategy with the strategic initiatives from seamless planning, delivery, and an entirety of service lifecycle. The SLM contains the SLA or an agreement between the service provider and the client (He, Yan, Kowalczyk, Jin \& Yang, 2009) and service consumers. SLA documents the type of service being supported or provided by the service provider, targets using a metrics, and defined roles and responsibilities of both service provider and client.

The core document or repository of the service is contained in a service portfolio. In some cases, a service portfolio is composed of the list of services provided by the organization. This service provider has also the Service Catalogue (SC) which is a segment of part of the portfolio. The includes the details about the service providers deliverables to the client, milestones, the cost, and estimate or service pricing, service contact details, and other documentary needed such as order fulfillment and requisition pro- cess. The Service Provider will design its Service Strategy based on its technology infrastructure and capabilities to deliver the service based on the SLA. SLA is measured using a service level measures; such as the performance of a technology, performance of the system and support team, or the frequency of specifically dedicated workaround to fallout. Service level is the achieved performance of the service provider over the service targets. Most commonly used metrics to quantify performance are number of resolved or answered calls, hour, minute and second based on the Mean Time To Repair or Mean Time To Resolve (MTTR). An MTTR is the measure of the average speed of service repaired, excluding the time spent for service restoration from the service failed state.

\section{Business Process Innovation using LSS}

A sigma is a statistical measure used to quantify the variability in a process also known as Standard Deviation. A Six sigma is a data-driven and disciplined approach to measure and improve the organization's operational performance by identifying and eliminating "defects" in manufacturing and service-related processes. Six sigma works in manufacturing and service industries. Companies are measured and described based on the performance of its processes to the specification limits. Six Sigma level has 3.44 defects per million opportunities (dpmo) and defect rate with a yield of $99.99966 \%$. A process sigma level 2 has 308,770 (dpmo) defect rate and yield of 69.1\%; sigma level 3 has 66,811 (dpmo) defect rate and $93.3 \%$ yield; sigma level 4 has 6,210 (dpmo) defect rate and 99.38\% yield; sigma level 5 has defect rate of 233 (dpmo) and 99.977\% yield. The ramifications of process innovation were championed by the Japanese companies and even corporation sprung the derivative of having a streamlined work-flow processes and gainful competitive advantages (Robson, 2010; Ward, 1994). Pande, Neuman \& Cavanagh (2000) emphasized how GE, Motorola, AlliedSignal, and other top companies swept corporate America by honing the business performance and further achieved extraordinary financial and market share using Six Sigma (Harry \& Schroeder, 2005). Six sigma is a business strategy which leads to significant profit and gains through service quality, productivity, and customer satisfaction as (Antony \& Banuelas, 2002; Harry, 1998 ) postulated. Six sigma capitalizes on a disciplined approach even used in the academic perspective by means of application of statistical and non-statistical tools and techniques (Antony, 2004). Although there were phenomenal implications of Six Sigma and acceptance in several orga- 
nizations Linderman, Schroeder, Zaheer \& Choo (2003) repercussions to sustainability, the need to comprehend the Six Sigma key and potential features, lesson learned, and best practices can better the implementation of kaizen or six sigma projects Kwak \& Anbari (2006) to brook continuous improvement. Linderman et al. (2003) contend that despite the company's financial success, product, and service quality, Six Sigma, as goal-theoretic still lacks theoretical foundation other than best practices for internal and external quality management system.

Adams, Componation, Czarnecki \& Schroer (1999) scholarly contribution to the existing knowledge in continuous improvement process describe tools in lean manufacturing embarked to process performance improvement opportunities in the quality of operations (Saraiva \& Stephanopoulos, 1992). Because of the changes and advent of technologies, market demands, customers' buying patterns and business model, service industry organizations have had reinvigorated their way of service provisions, engaged in service process innovation, and implemented lean thinking to improve product quality and increased its value. George \& George (2003) offered their work which combined Lean Manufacturing and Six Sigma to speed up and improve product quality, and reduction of variation through waste elimination in the production (Furterer \& Elshennawy, 2005; Dasig Jr et al., 2014). In Byrne, Lubowe \& Blitz (2007) work of using a LSS approach to drive innovation, it was emphasized and described the rudiments of LSS methodologies as the driver to improve the operations, process, and product improvement, service value, service markets, and the underpinning business model of the commercial enterprise. A product or service value is anything related to or associated with a product or service which the customers are willing to pay for. Any activity or undertaking, which is translated into process improvement, can be attributed as value mapping after value assessment has been made. Service value or product value is always stated in the perspective of the customer, so does wastes. Anything which is not value-adding is waste. This paper presents organizational steps into Lean Thinking and Six Sigma world. This will report the impact of a LSS Kaizen project on the business performance in terms of productivity, and efficiency improvement using a DMAIC approach (Ramanan, Kumar \& Ramanakumar, 2014).

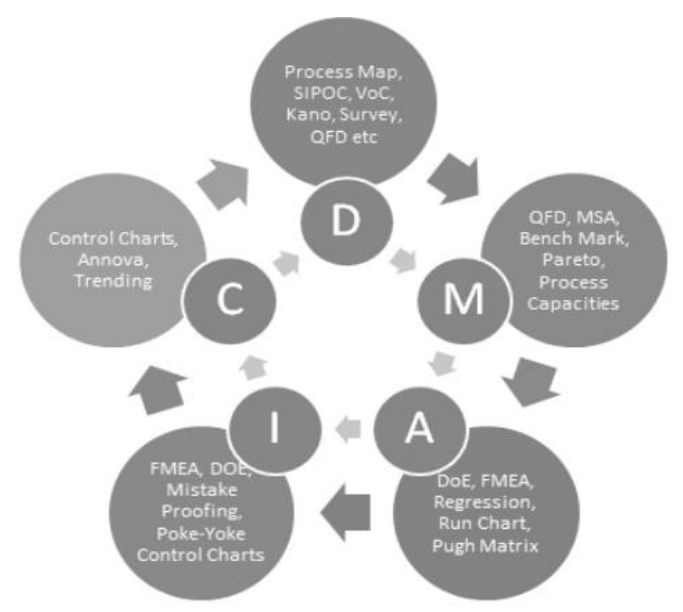

FIGURE 1. DMAIC approach (Ramanan et al., 2014)

\section{METHODOLOGY AND KAIZEN PROJECT RESULTS}

The methodology employed in the project used by the researcher was the DMAIC methodology. It is a data-driven LSS methodology used in the process improvement cycle for improvement design, improvement optimization, and continual process and design management as illustrated in Figure 1. In the design phase, trend analysis was used to capture the data trends in the organization, identify the performance baseline, entitlement, and goal necessary for designing efficiency improvement. During the Measure Phase, a high-level process map Supplier Input Process Output Customer (SIPOC) Diagram was utilized to sketch significant elements in the process improvement to be etched. Pareto Diagram was used to identify the $20 \%$ vital pro cesses as the major contributor to the problem and Ishikawa Diagram (Fishbone analysis) used for Cause and 
Effect Analysis during the Analyze Phase. In effect of the improvement design during the Improve Phase, the Possi ble, Implement, Challenge, and Kill (PICK) Chart was used to categorize Lean events from ideation to implementation, process creation, and process innovation undertaken. Process Capability Index $\left(\mathrm{C}_{\mathrm{pk}}\right)$, Process Performance $\left(\mathrm{P}_{\mathrm{p}}\right)$, and Process Performance Index $\left(\mathrm{P}_{\mathrm{pk}}\right)$ were also used to measure if the improvement in the process can deliver and satisfy the services being supported. Out-of-Control Plan (OCAP) and Reaction Plan, Control Charts, and Dashboard were designed and developed for the Control Phase.

\section{Define Phase: Kaizen Project Problem Statement}

The wireless and wireline provisioning services have been running for years with a construed SLA of MTTR of 15 minutes and $75 \%$ daily resolution with the service owner.
Due to the service's higher demands and technology's major changes deployment, a department provisioning the service support has had the averages of $66.60 \%, 65.90 \%$, $65.20 \%$ and $64.50 \%$, monthly service resolution under the queue management in January, February, March, and April respectively. From January to April, Wireline Support Group (WSG) of Service Support Department had received service demands and escalated issue for remediation and resolution, and had an accrued increase of MTTR from 50 to 150 minutes, respectively. Non-resolution of these service escalations and daily fallouts directly impacted thousands of customers. This had resulted to customers' dissatisfaction, the department's SLA, and to the business. Figure 2 illustrates the 4 months Wireline Support MTTR Performance from January-April.

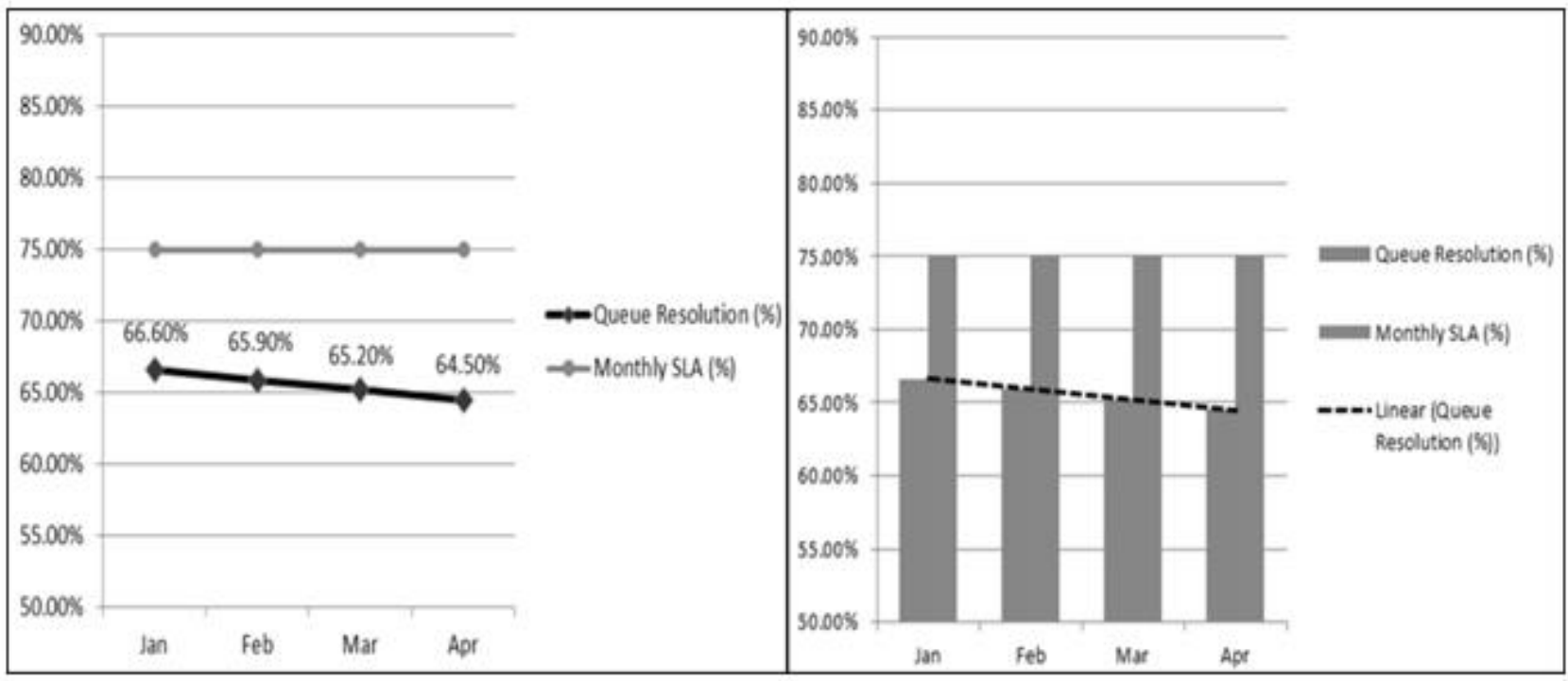

FIGURE 2 . The wireline support group mean time to resolved performance (Jan-April)

\section{Project Objectives and Scope}

The Kaizen Project aimed to (a) devise a functional process innovation, (b) employ LSS as business process improvement methodologies, (c) develop a one-time service fallout resolution scheme, and (d) develop a queue management process to improve the department's current average performance of $65.55 \%$ to meet and exceed the SLA. The process devised will be owned by the Service Support Department which includes the Leadership Team, Wireless Services Support Group, Wireline Services Support Group, Tester and Deployment Team, and Quality Assurance Team for the Defect Management.

\section{Goal Computation}

The metrics defined in the SLA are in (minutes). The MTTR of WSG for January (50 min), February (65 mins), March (120 min), and April is 150 minutes. The support group's average MTTR is 96.25 minutes. Computed Goal (x) can be obtained using the formula;

$x=y-(y-z)^{*} 70 \%$

Computed Goal $=$ Baseline $-($ Baseline - Entitlement $) * 70 \%$ where;

$x=$ Computed Goal.

$y=$ Baseline, or the average current process performance of the WSG. 
$z=$ Entitlement, or the WSG best performance attained so far.

The Computed Goal is;

$x=96.25 \mathrm{~min}-(96.25 \mathrm{~min}-50 \mathrm{~min}) * 70 \%$

$x=63.88 \mathrm{~min}$

Based on the current average performance of the WSG, the MTTR baseline is 96.25 minutes which is attributed to be more than $600 \%$ non-meeting to the 15 minute process SLA. In the 4 month MTTR, the support group is entitled to $50 \mathrm{~min}$ which is the best performance recorded in the month of January.

\section{The Business Impact}

Dissatisfied customers on the services are likely to churn and will impact the business. Reduction in support group Mean Time to Resolved will result to an increase in support group's productivity by $33.63 \%$.

$a=(y-x)^{*} 100 / y$

Efficiency Improvement $=($ Baseline-Goal $) * 100 /$ Baselin

where;

$a=$ Efficiency Improvement

$y=$ Baseline

$x=$ Goal

Efficiency Improvement;

$a=(96.25 \mathrm{~min}-63.88 \mathrm{~min}) * 100 / 96.25 \mathrm{~min}$

$a=33.63 \%$

The performance metrics of the support group are measured in (minutes). Based on the agreed and carefully designed SLA, a daily MTTR of 15 minutes to at least 75\% resolution rate was delivered to the client. The support group had an average MTTR for the months of January of (50 min), February (65 min), March (120), and April (150).

\section{Trend Analysis for WL Support Group}

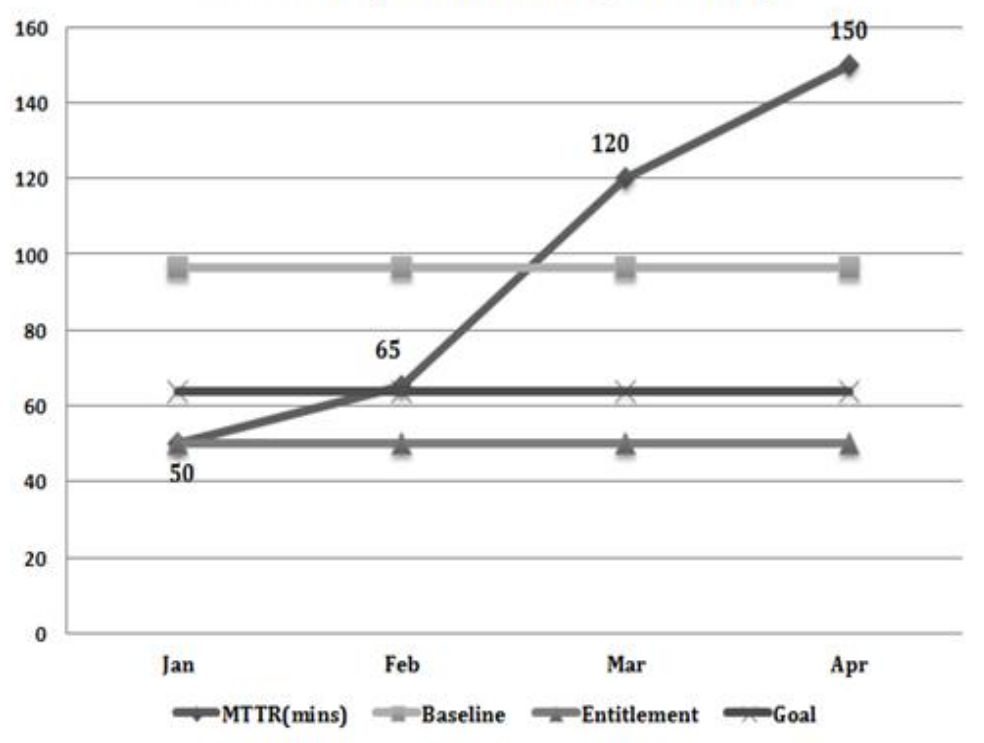

FIGURE 3. Trend analysis for the 4 month WSG mean time to resolved, baseline, entitlement, and goal

With the recorded performance, basis for business process improvement Baseline is 96.25 minutes, an Entitlement of 50 minutes, and the Computed Goal is 63.88 or 64 minutes as depicted in Figure 3 which shows the Trend Analysis for the 4 Month WSG, MTTR, Baseline, Entitlement and Goal. The Figure 4 shows the existing Queue Fallout Management Procedure. A queue bin is the collection of submitted fallout issues from other support teams housed in an enterprise software application. These fallout issues are service incidents, problems, and complaints that have to be remediated or resolved by the WSG. Fallout issue will be analyzed by the support group member and would gauge if there are workaround to the known issue. The support group member shall take ownership by assigning it to his name, otherwise release it and return to the queue. A remediation workaround will be applied to fix the fallout. 
In the event of successful remediation, the fallout will be tagged as remediated and closed; otherwise a resolution team will handle the fallout and apply a resolution workaround. When the application of resolution workaround is able to fix the fallout issue, it will be tagged as resolved and close the fallout, otherwise it will be released and returned to the queue.

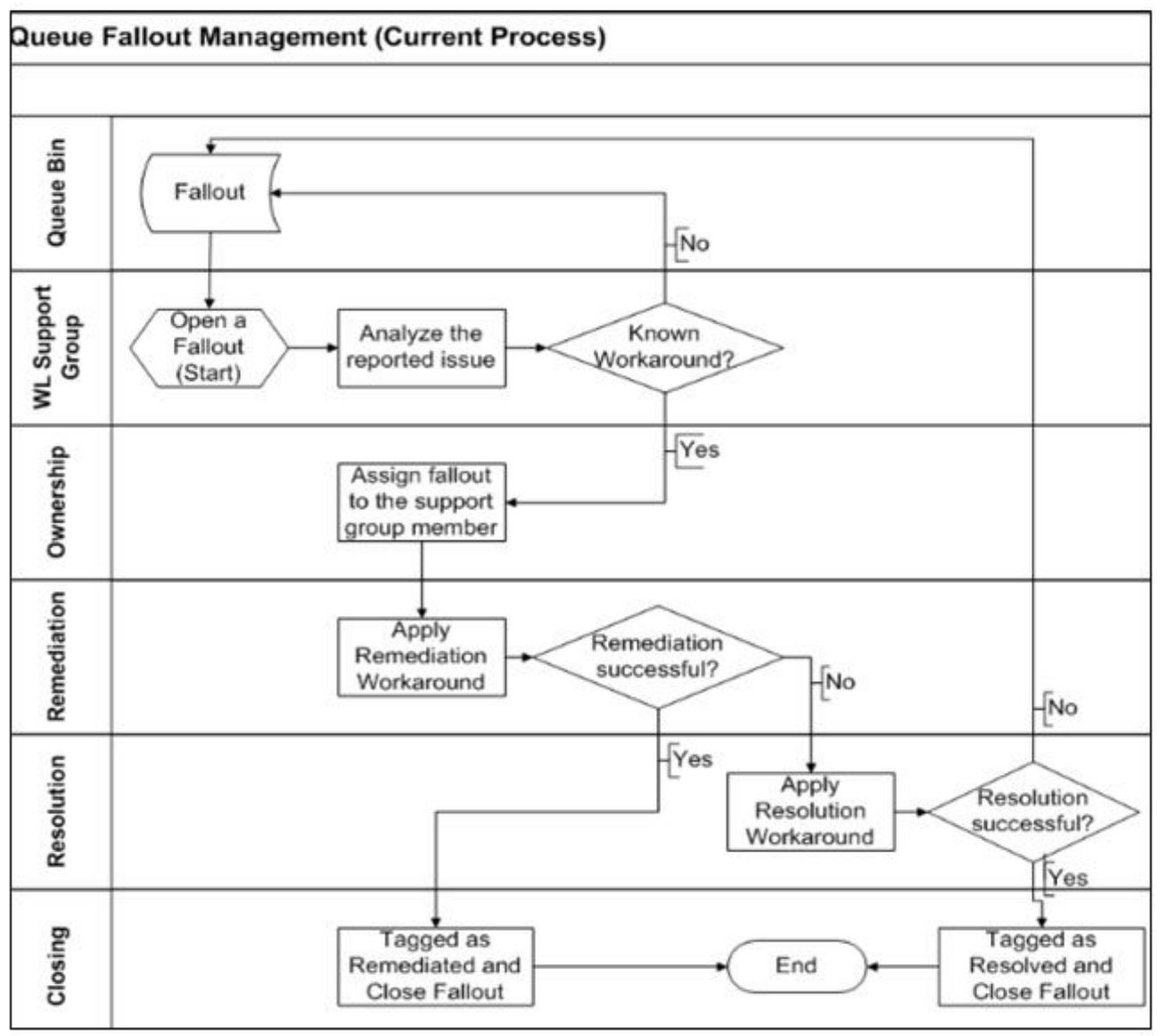

FIGURE 4. Queue fallout management procedure

\section{Measure Phase: SIPOC Diagram}

The SIPOC Diagram was used in this project in aid of sketching and identification of all relevant and significant elements in the business process improvement. SIPOC diagram is a high-level process map Brewer \& Bagranoff (2004) which is primarily used to provide visualization to optimize supplier input resources, Antony, Krishan, Cullen \& Kumar (2012) to a service process, take actions and tools Desai \& Shrivastava (2008) and deliver customer's desired products and services (Yang \& El-Haik, 2003). It outlines and simplifies complex project into comprehensive chunks to be well-scoped in a LSS, DMAIC methodology. The dia gram helps business to understand and visualize its business processes. The Figure 5 presents the SIPOC Diagram used in this process innovation. Suppliers are the people and instrumentalities which supply input to the process which includes the Talent Acquisition (HR, Leadership and Capability Management, Knowledge Management, Technology, Information Technology, and Client). Inputs are those elements which are contributory to how the process can be carried out, and are the basis for designing the business requirements. Inputs in this project under study include the support group applicants profiled and undergone talent acquisition processes, hired applicants endorsed to training group, support group trained on processes, technology and tools using a dedicated service specifics training curriculum, trainees given the privileges and access rights to the applications and tools and the support group trained on internal and external quality management systems. The inputs to SIPOC diagram have bundles of requirements to pro- 
duce a required output commonly known as Input Requirements. This project has listed input requirement such as support group trainee passes the WL training assessment and job-shadowing; support group trainee has functional access rights to the applications, technology, and tools; support group trainee is mentored, coached and evaluated on daily and weekly basis and support group trainee adheres to the quality of work. In a service management context, input requirements are attributed to as input parameters in the service delivery.

The processes found to be improved are the Ownership, Remediation, and Fallout Resolution. The processes are ac- tivities carried out to translate inputs into outputs. Fallout ownership denotes as assigning of fallout issues to a team member, a remediation team or a resolution team. For instance, a team member who first opened the fallout in the Queue gauged that the issue can be resolved by him, the same issue will be assigned to his name, otherwise to the other team member in the support group, to remediation or resolution team. Remediation is the application of immediate action to remedy fallout issues, bugs or fixes while Resolution is the application of contentious workaround to resolve known fallout issues, bugs, and fixes. These processes are tinted under the WL support group and service delivery.

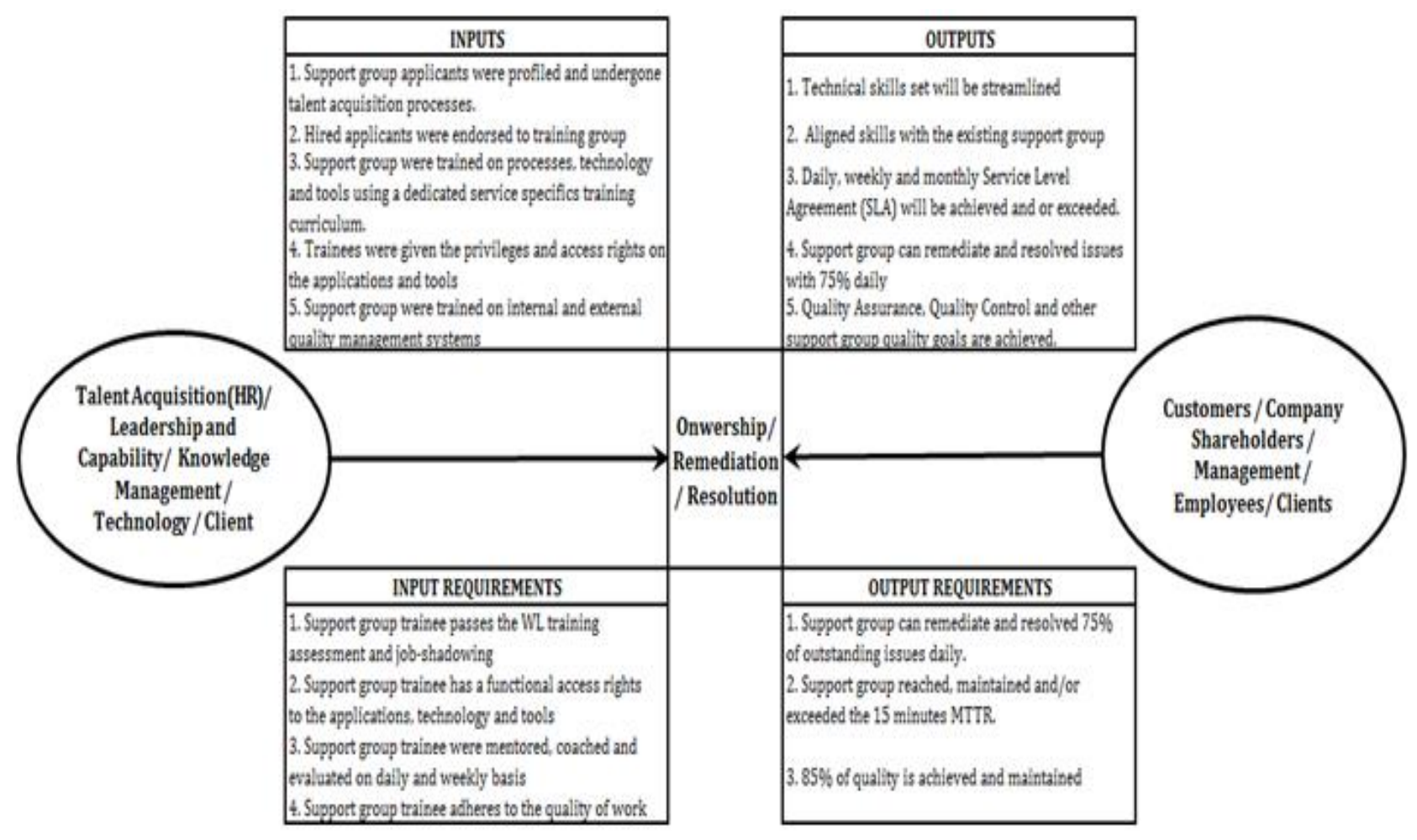

FIGURE 5. SIPOC diagram

Outputs are those translated and processed inputs. In this SIPOC, outputs include technical skills set that will be streamlined, aligned skills with the existing support group, daily, weekly, and monthly SLA will be achieved and or exceeded, support group can remediate and resolve issues with 75\% daily Quality Assurance, Quality Control and other support group quality goals are achieved. Output requirements are mounted to the input requirements of a business system or business process. In a service-oriented organization, output requirement is always linked to the SLM as the organization's way of keeping abreast with their SLM. In the service supported by the WL Support Group, output requirements include; support group can remediate and resolve $75 \%$ of outstanding issues daily, the support group can reach, maintain, and/or exceed the 15 minute MTTR and at least $85 \%$ of quality is achieved and maintained. 
Analyze Phase: Pareto Diagram and Ishikawa Diagram (Fishbone Analysis)

\section{Identifying the problem focus using pareto diagram}

The Pareto diagram is a powerful graphical tool or a special bar chart Johnson, Miller \& Freund (2000), Frakes \& Fox (1996) that presents clear information Sokovic, Pavletic \& Fakin (2005) and helps to determine the element of major contributor in a process (Eiden et al., 2007). Sokovic et al. (2005), posited that Pareto diagram can provide domains of the process for possible improvement. Pareto diagram can be constructed by ranking or sorting the frequencies or relative frequencies Wilkinson (2006) of the attributes or data sets from the highest to the lowest frequency value or occurrence (Frakes \& Fox, 1996) further. Pareto diagram also known as Pareto chart is a significant tool when the process improvement effort is going to establish priority focus on the factors that offer the greatest potential for improvement. The Pareto principle was 1 developed by Vilfredo Pareto who was an Italian economist who linked the $20 \%$ Vital few and $80 \%$ trivial many. The processes with the frequencies are presented in Table 1. The WSG.

TABLE 1. The WSG AHT in fallout issue resolution

\begin{tabular}{|c|c|c|c|}
\hline Queue Managament Procedure & AHT in (min) & $\%$ Contribution & $\%$ Cummulative \\
\hline Applying resoultion workaround & 150 & $49.8 \%$ & $49.8 \%$ \\
\hline Re-opening the fallout from the queue & 100 & $32.2 \%$ & $83.1 \%$ \\
\hline Applying remediation workaround & 10 & $3.3 \%$ & $86.4 \%$ \\
\hline Analyzing the reported fallout & 15 & $5.0 \%$ & $91.4 \%$ \\
\hline Returning the fallout to queue if resolution failed & 5 & $1.7 \%$ & $93.0 \%$ \\
\hline Tagging the fallout as remediate, if remediation successful & 3 & $1.0 \%$ & $94.0 \%$ \\
\hline Tagging the fallout as resolved if resolution has been made successfully & 3 & $1.0 \%$ & $95.0 \%$ \\
\hline Assign to the support group if known wordaround & 3 & $1.0 \%$ & $96.0 \%$ \\
\hline Returning to the queue (L1) & 5 & $1.5 \%$ & $97.7 \%$ \\
\hline Assign to resoultion team if remediation failed & 2 & $0.7 \%$ & $98.3 \%$ \\
\hline Close the fallout if remediated successfully & 2 & $0.7 \%$ & $99.0 \%$ \\
\hline Close the fallout if resolved successfully & 2 & $0.7 \%$ & $99.7 \%$ \\
\hline Opening the fallout & 1 & $0.3 \%$ & $100.0 \%$ \\
\hline
\end{tabular}

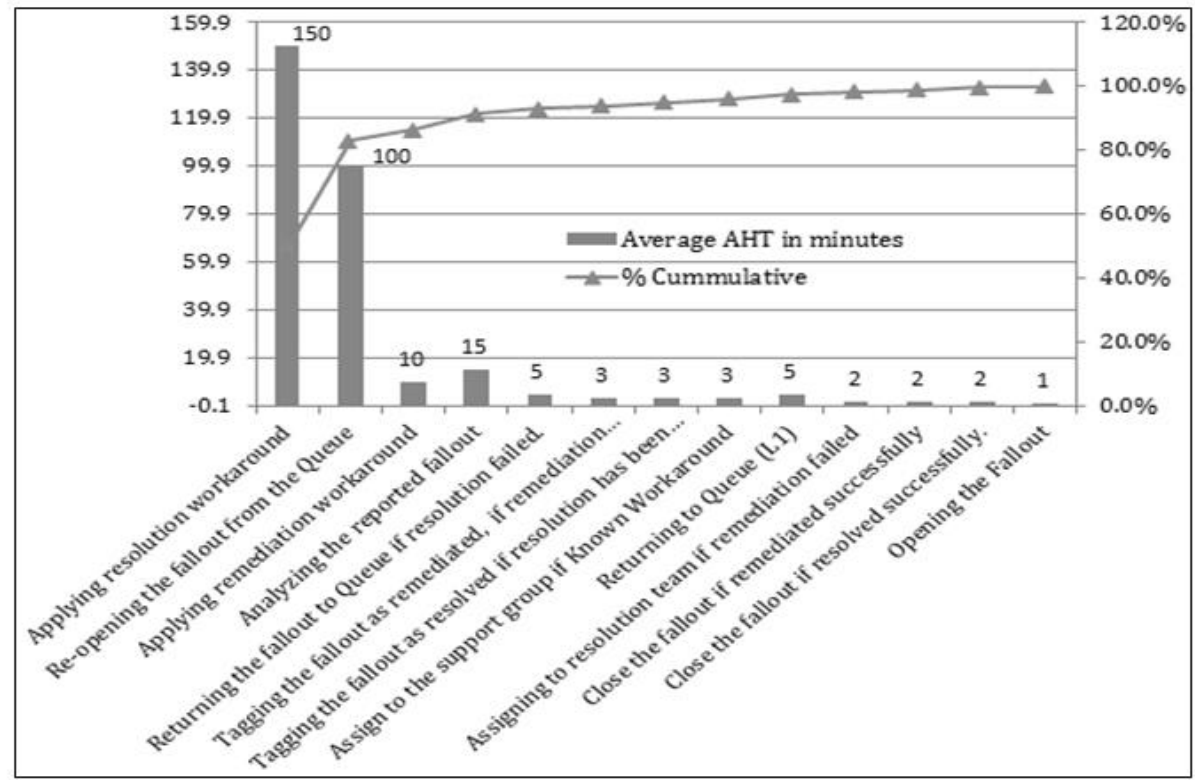

FIGURE 6. The pareto chart for fallout queue management 
Average Handling Time (AHT) in Fallout Issue Resolution. It provides processes, the AHT in each process, \% contribution of each process, and the percentage cumulative. In Figure 6, the characteristics or the processes of queue management were ranked from highest to lowest frequencies using the metrics (minutes). Figure 7 is a Pareto Chart for the Fallout Issue Queue Management with the emphasis on the 20\% Vital and 80\% Trivial for Fallout Queue Management. Based on Figure 8, the major problem contributors are the redundancy of applying resolution workaround, and re-opening the fallout from the Queue.

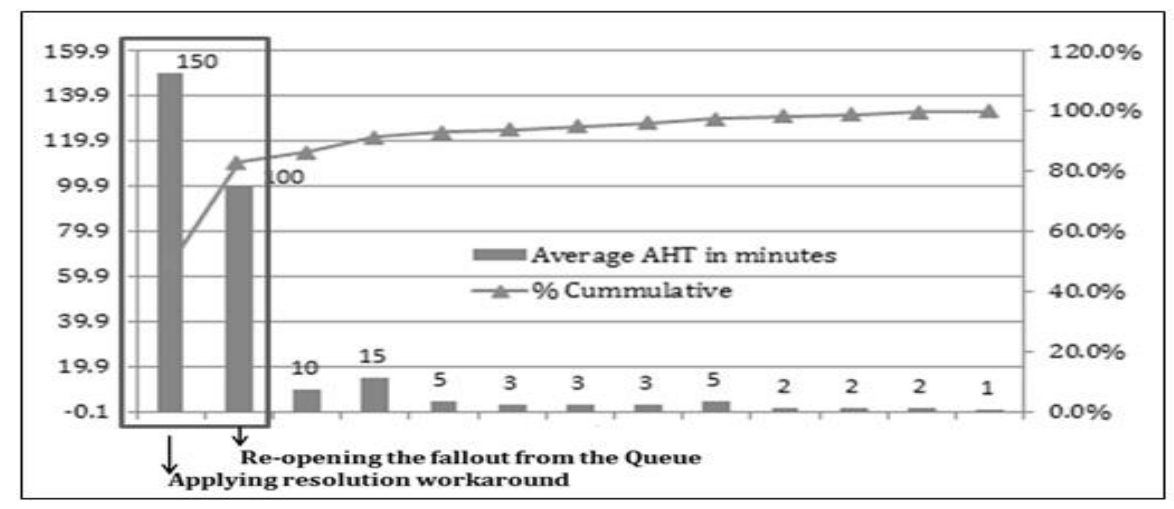

FIGURE 7. Pareto chart with $20 \%$ vital and $80 \%$ trivial for fallout queue management

\section{Ishikawa analysis (Fishbone diagram)}

The Ishikawa Analysis or commonly known as Fishbone Diagram is used in the identification of the causes of a problem (Bicheno, 1998; Goetsch \& Davis, 1994; Psychogios \& Priporas, 2007). The fishbone diagram is commonly referred to as Cause and Effect Diagram invented by Dr Kaoru Ishikawa (Ishikawa \& Lu, 1985; Chang \& Lin, 2006) and is commonly employed to summarize causes or contributing attributes to the effects. The highest causative rudiments which directly impacted the WSG, MTTR is Applying Resolution Workaround which is 150 minutes; a $1000 \%$ below its SLA of 15 minutes. The workaround is the method or process of carrying out a remediation or resolution procedure to a known incident or problem. In a service management using the ITIL context, the incident is defined as disruption or a system activity which is not normal in nature while problem is the occurrence of multiple incidents. Restoring a service to its previous state or configuration requires workarounds which are free from bugs, tested by the developers and approved for deployment in all service environments to production.

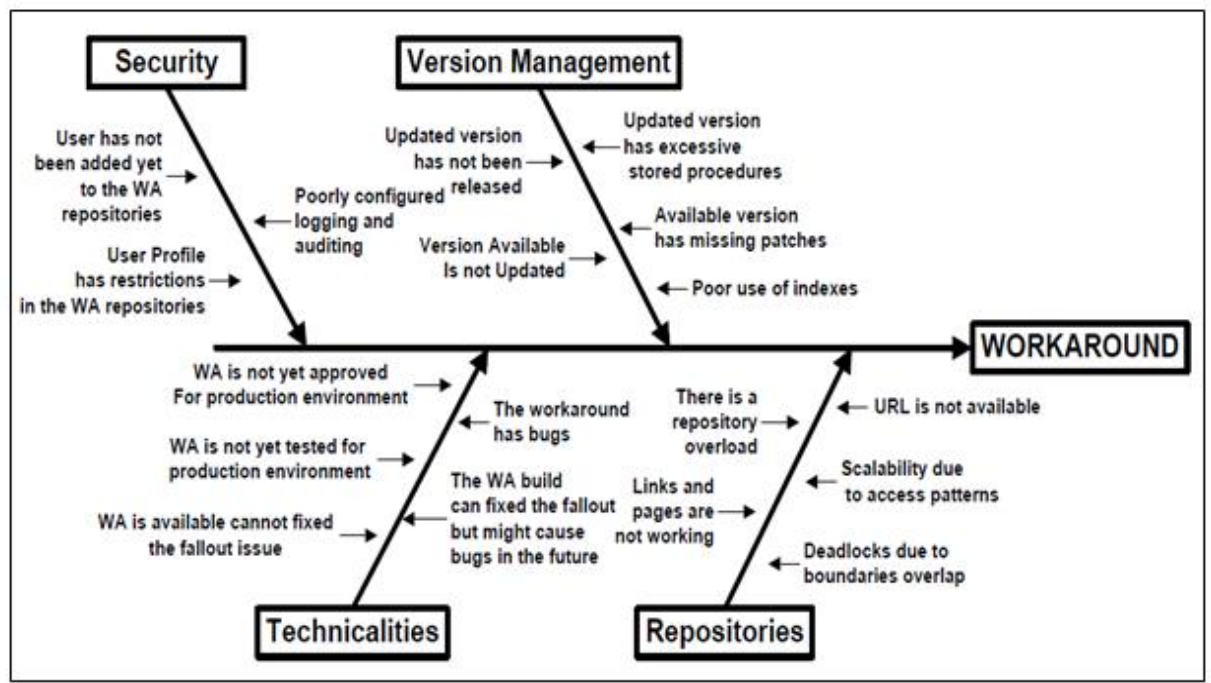

FIGURE 8. Ishikawa analysis (Fishbone diagram) for workaround 
The Figure 8 illustration served as the researcher's reference as to how to dig the problem into chunks of causes. It was found that applying workaround AHT with 150 minutes, subject to careful investigation of what and why it took that long. Ishikawa Analysis was used to figure-out and perform the root-cause analysis. Figure 9 shows Workaround as Vital 20\% and major contributor to the group's MTTR below $15 \mathrm{~min}$, there were causes identified to wit; version management, security patches, repositories, and technicalities must have been considered by the WSG as causes to why it took 150 minutes to apply workaround for certain fallout issues.

It was identified that in the auspices of version management; workaround may have been updated version having excessive stored procedures, available version has missing patches, poor use of indeces, the version available is not updated, or updated version has not been released. Another cause is the storage and repositories management with identified cause that there is a repository overload, the links and pages are not working, the URL is not available, there has been scalability due to access patterns and there were deadlocks due to boundaries overlap. Perhaps, there have been QA always, however, there are at times system changes that imply either major or minor, the workaround has bugs, the WA build can fix the fallout but might cause bugs in the future, WA is not yet approved for production environment, WA not yet tested for production environment, and WA is available cannot fix the fallout issue. These technicalities are also associated with security issues such as user has not been added yet to the WA repositories, a user profile has restrictions in the WA repositories and there has been poorly configured logging and auditing. Based on the queue software application analytics; re-opening the Fallout from the Queue with 100 minutes is dependent on the multiple handling of the fallout issue from first to open the fallout, to the remediation, and to the resolution teams. It was consistent and true since a failure of remediation or resolution will opt them to return the fallout to the queue. Returned fallouts to the queue will be open again by another support group member, opened by another member again until the fallout has been further resolved.

\section{Improve Phase: PICK Chart, Process Innovation and its Implications}

Business Process Innovation through improvement efforts must be equated in terms of gainful benefits and resources put forward. A PICK Chart is a powerful matrix Rossi, Taisch \& Terzi (2012) categories that were put in the quadrants of possible, implement, challenges, and kill BornemannShepherd et al. (2015) gauged how easy to difficult each item is. It is a prioritization matrix in organizing recommendations Barber et al. (2015) and relevant metrics as process and implementation roadmaps (Atallah \& Ramudhin, 2010). A process improvement chart was used to categorize ideas from ideation to implementation of the business process improvements. The PICK Chart is one of the LSS Tools used in the categorization of ideas and process improvement in any LSS activity.

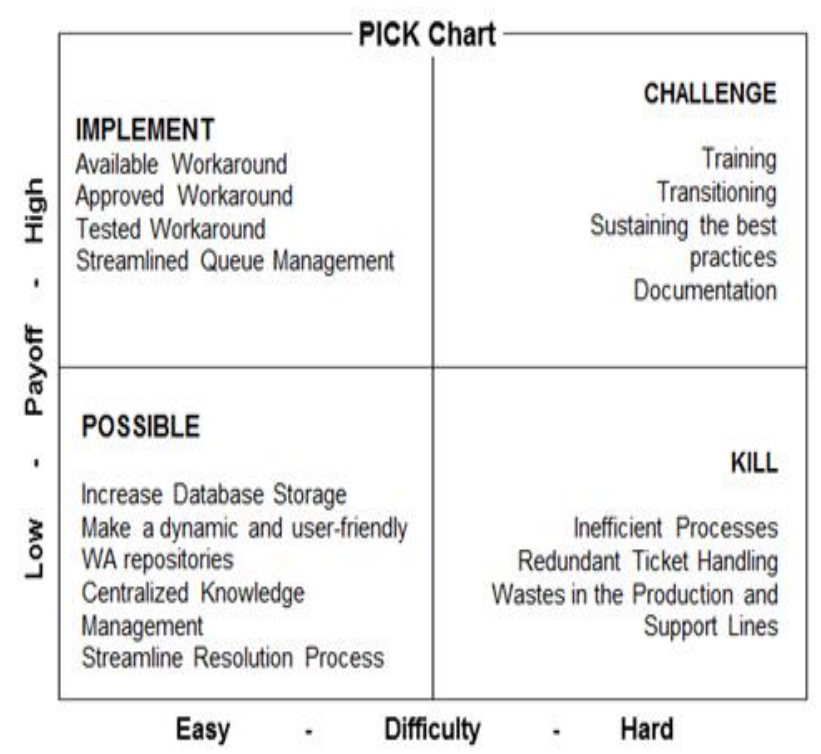

FIGURE 9. The PICK chart

In this Kaizen Project, Possible quadrant of the $2 \times 2$ grid illustrated in Figure 9 the recommended idea for consideration and improvement as to increase database storage, make or develop a dynamic and user-friendly WA repository, Centralized Knowledge Management and Streamlined Resolution Process. It was identified and is highly regarded to implement available workaround, approved workaround, tested workaround and streamlined queue management. Hence, there were identified shortcomings which are attributed to the current process weaknesses and challanges for the support group that have to be countervailed are the training or Knowledge Transfer (KT), transitioning, sustaining the best practices and crafting the functional documentation. With the eventual project Kick-Off, Inefficient Processes, Redundant Ticket Handling, Wastes in the Production and Support Lines were recommended to be considered in the KILL quadrant. A process improvement has been constituted and is presented in Figure 10. 


\section{Business Process Innovation and its Implications}

Designing new marque of becoming more efficient serviceoriented organization is a challenging enterprise. Theoretically, smearing Lean and Six Sigma methodologies can address waste elimination in the processes and could lead to increase gained benefits in terms of productivity, performance and effective service management. With the service design and process analyses being made, this paper presents the business process improvement which undermines that it could lead and lag the gaps in fallout management. A business process improvement cycle has been considered which has identified inefficient processes that could be broken or eliminated, reaffirming processes to be retained to craft a streamlined and waste-free process based on the improvement objectives. First imitative in this project was formation of the Roles and Responsibilities which are dedicated to every part of the team. The WSG is manned with the WSG Point of Contact (POC) who oversee the Incident Management Prime, Problem Management Prime, Incident Analyst, Problem Analyst and Defect Analyst as presented in Table 2 .

The WSG POC is a service support group focal point of information which concerns the service being supported. He oversees the entire group in terms of the metrics, com- pliance to SLA, performance and other administrative functions. The Incident Management Prime is responsible for managing the Incident Management Team with Incident Analyst in restoring the service as quickly as possible. He is likewise expected to generate reporting of team performance, SLA, and categorization of incidents and assigns incidence to Incident Analyst. The Problem Management Prime is responsible for managing the Problem Management Team with Problem Analyst in capturing the service life-cycle problems, reporting of team performance, SLA, and categorization of problems and assigns problem to Problem Analyst. An Incident Analyst is responsible for identifying, categorizaing and resolving fallout issues by applying the workaround to restore the service and minimize business impact while the Problem Analyst is responsible for the prevention of recurring incidents from happening again by problem detection, logging, and prioritization, diagnosis and reduction of its impacts on service and business. Those incidents or problems which were not fixed by the workaround will be handled by Defect Analyst who manages defects queue, defects tracking and monitor resolutions of defects activities such as script development, and other Quality Assurance capabilities.

TABLE 2 . The WSG roles and responsibilities

\begin{tabular}{ll}
\hline \hline Role & AHT in (min) \\
\hline WSG POC & A service support group focal point of information which \\
& concerns the service being support. He oversees the entire group in terms of the \\
& metrics complaince to SLA performance and other other administrative functions \\
Incident mangament prime & Responsible for managing the the incident managment team with \\
& incident analyst in restoring the servive as quickly as possible. \\
& Responsible for reporting of team performance, SLA and \\
& categorization of incident. Assigns incident to incident analyst. \\
Problem managment prime & Responsible for managing the problem management team with problem \\
& analyst is capturing the service life-cycle problems. \\
& Responsible for reporting of team performance, SLA and categorization of problems. \\
& Assigns problem to problem analyst \\
Responsible for identifying, categorization and resolving fallout & issues by applying the workaround to restore the service and minimize \\
business impact & Responsible for prevention of recurring incidents from happening \\
Problem analyst & again by problem detection, logging and prioritization, diagnosis anf reduction \\
& of its impacts to service and business. \\
Manages defects queue, defects tracking and monitor resolutions of \\
defects activities such as script development, and othe QA capibilities.
\end{tabular}




\section{Knowledge Management System}

In the PICK chart, a centralized Knowledge Management or WA repositories have been pooled on the possible quadrant, considerably and conscientiously. It was realized so that every support group member will share common knowledge and best practices in fallout resolution. Figure 10 is the Graphical Description of the WSG Knowledge Management System (Wiki) which provides high-level view of the system, an information system which manages knowledge of WSG and the organization as Dasig Jr, (2014) emphasized the need for information system as enabler for its operational excellence. Knowledge Management (KM) system is the web or computer-based application referred to as the creation of knowledge repositories, and improvement of knowledge access Abdullah, Selamat, Sahibudin \& Alias (2005) which has become imperative for most worldclass companies Lee \& Hong (2002) and service-oriented organizations success (Chait, 1999). Knowledge management system is application software used to consolidate workarounds to fallout issues, incident or problems; re- trieve service related information, documentations, class or category of incidents and problems, taxonomies and ontologies, and autocontextualizer (Copperman et al., 2004).

The WSG Wiki of Knowledge Management System for WSG was developed using PHP and MySQL for the relational database. The system includes login module, File Maintenance Module (Add, Edit, Delete a Fallout Issue, Incident, Problem or Defects Workaround), Transaction Modules for the users, and Audit Logs. A search capability for workaround retrieval has been designed based on the user needs. It contains a database, a record of WA, a knowledge item, type of Fallout Issue (Incident, Problem or Defects), knowledge accessor Havens (1999), and release alerts for the defects fixed. Administrative and access rights are controlled based on the user profiles of the WSG group nature and scope of work. KMS developers were sourced from the organizations application developers and staged with User Acceptance Tests. Workarounds in the KMS are those tested and approved in the development, testing, pre-production and production server environments.

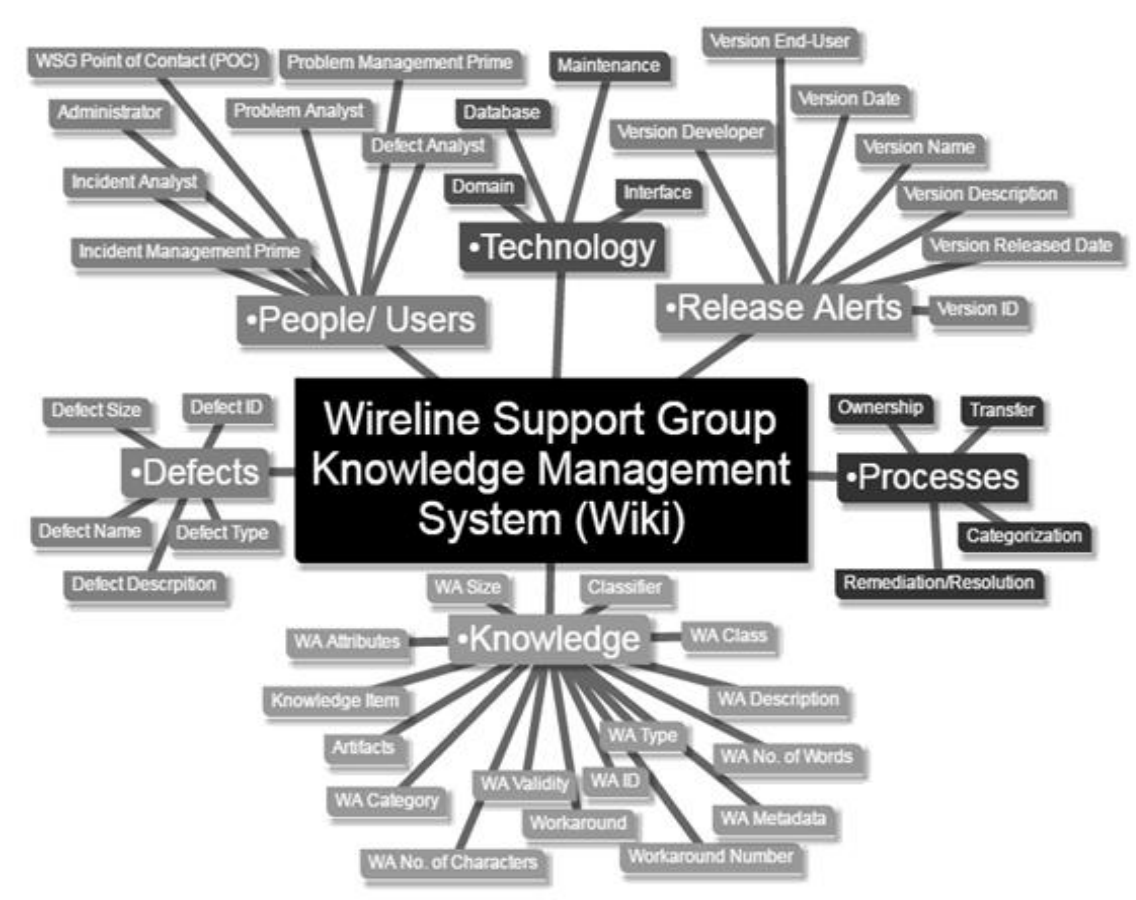

FIGURE 10. The graphical description of the WSG knowledge management System (Wiki)

\section{Process Improvement for Queue Fallout Management}

The corollaries of business process improvement embarked on improving service quality Rummler \& Brache (2012) while eliminating deadly wastes Dasig Jr \& Gatpandan
(2013) can be catapulted by redesigning the business process and apply the transformative function of information technology (Chiarini, 2012; Cole, Goldberg \& White, 2004; Davenport \& Short 1990; Mumford, 1994). The process im- 
provement being advocated in this project is the elimination of redundant and inefficient processes from the existing fallout issue resolution. The summary of roles and responsibilities of the support group is the backbone of fallout resolution with the help of the Knowledge Management System developed and deployed dedicated for the support group. The Pareto Chart showed workaround to be the main contributor, with the result of Fishbone Diagram; hence a KMS can be an elucidation to countervail the causes of the problem. Table 3 is the streamlined and improved Queue Management Procedure for the WSG. One-time handling and resolution of the fallout is being advocated in the process improvement which implies, that once fallout has been opened by an analyst, it must be resolved or tagged as defect.

TABLE 3 . The WSG new queue managment

\begin{tabular}{ll}
\hline \hline Role & Process \\
\hline Incident analyst & 1. Open the fallout from the queue \\
& 2. Filter incident fallout \\
& 3. Assign to (your name) \\
& 4. Apply workaround for a known incident fallout. \\
& 5. If resolved, tag as reolved and close otherwise tag with a defect \\
& and transfer to defect support group \\
Problem analyst & 1. Open the fallout from the queue \\
& 2. Filter problem fallout \\
& 3. Assign to (your name) \\
& 4. Apply workaround for a known problem fallout. \\
& 5. If resolved, tag as reolved and close otherwise tag with a defect \\
& and transfer to defect support group
\end{tabular}

Next step was to streamline the fallout issue resolution system which is depicted in Figure 11, The New Queue Management Procedure. The essence of this organizational ramification and progression is of becoming a processcentric organization embedded in all facets of change Shtub \& Karni (2010) through radical redesign of its core processes Guha, Kettinger \& Teng (1993) and brand a coherent business processes with the improvement goal (Andersen, 2007). The core process in service provision of the WSG is the Queue Fallout Management. Thus the New Queue Fallout Management procedure removed identified wastes and is pegged to provide dramatic improvements in the support group productivity, increase MTTR, fallout handling and cycle times Guha et al. (1993) and service quality. The dynamics in the business model for process-centric and serviceoriented organization advocated on diagnosing the critical service success factors. In the service domain, process, and infrastructure were typically undermined and focused on macro-level (Jain \& McLean; 2005). In this new queue fallout management procedure, the timely diagnosis of the escalated incidents or problem Gupta, Prasad, Luan, Rosu \& Ward (2009) to the WSG queue was highly regarded. The rudiments of incident management are to classify, priori- tize those incident escalations and apply quick-fixes Bartolini, Sallé \& Trastour (2006) and Gupta, Prasad \& Mohania (2008) with high consideration of its impact on service, customers, and business as well as urgency. Fundamental to incident management is the problem management which comes into effect of improving the service infrastructure quality (Brenner, 2006), by investigating the Mean Time Between incidents and Mean Time between Failures. The process improvement herein handles the repercussions when incidents re-occurr. Athuraliya, Low, Li \& Yin (2001) presented a new active queue management scheme using the Random Exponential Marking (REM) to decouple congestion measure and achieve high utilization. The improved processes in Figure 12 included the Defect Management Tool being manned by a Defect Analyst who can impact a significant increase in Wireline WSG Mean Time to Resolve, capture the One-Time Resolution Scheme (OTRS) scheme for both incident and problem management. OTRS was advocated to eliminate the fallout hand-off as waste (Dasig Jr et al., 2014). In this Kaizen Project, the hand-off was attributed as the Re-opening of fallout issue that has been returned to the Fallout Queue. 


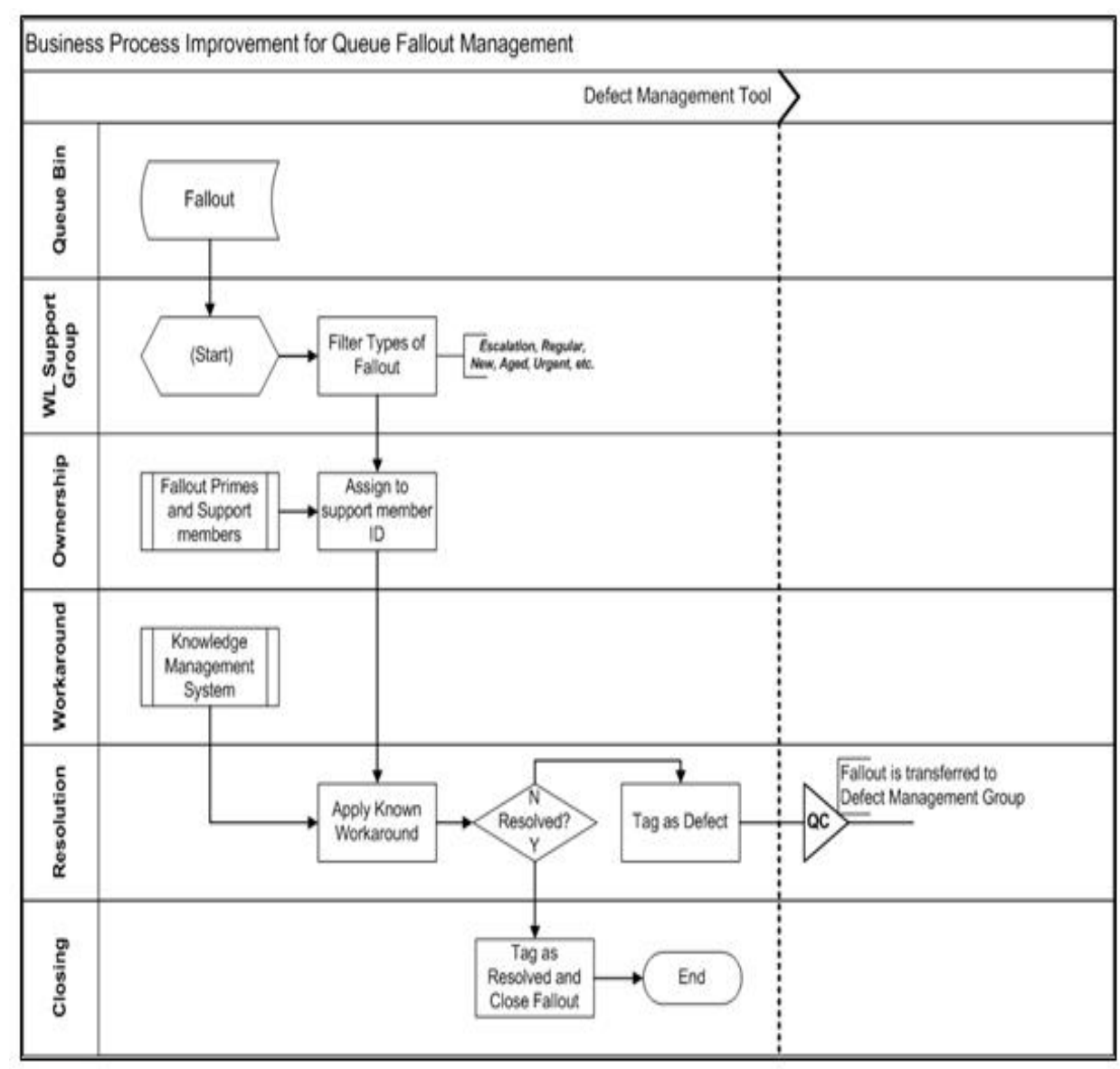

FIGURE 11. The new queue management procedure

\section{The Implication of the Kaizen Project}

The project was launched and implemented in the first week of May to effect the change in the fallout resolution. The WSG of the Service Support Department, a Knowledge Transfer has been made to provide the smooth transition from the current to the new process. Theoretically, it is the training conducted to allow the WSG embrace the change being implied and eventually sustains the new procedure implemented. There were KT sessions staged to acquaint the group with the various aspects to consider using the Knowledge Management System and the process improvement being made. Figure 13 describes the weekly performance of the Wireline Support group before and after the improvement has been made. As depicted in Figure 12, since the project was implemented, there were no variations in the performance of the team in which every other weeks, the performance is getting higher.

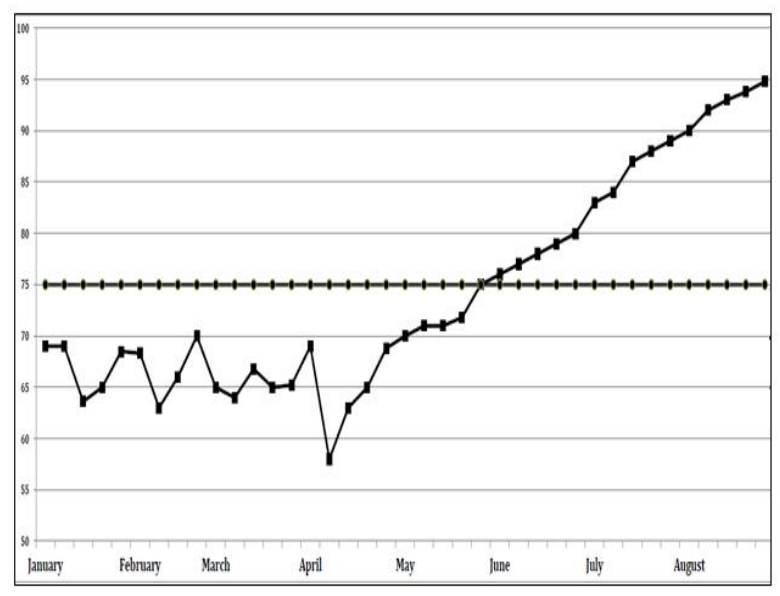

FIGURE 12. A weekly WSG performance before and after the Kaizen project implementation

Based on the Weekly WSG Performance after the project has been implemented, a significant increase in the $\%$ Resolved was observed. In the $5^{\text {th }}$ week of May, no less than a month after the process improvement implementation, the 
WSG met the $75 \%$ on a weekly basis as reflected in Figure 13. However for its monthly performance, the group exceeded the monthly $75 \%$ SLA in the month of June as shown in Figure 14 which is $78 \%$. During the first month of post-implementation, there was a recorded performance of $71.70 \%$ and consistent with the Lean Six Sigma project goal of continuously improving the performance, there has been a continuous increase in the performance bars of 78\%, $85.50 \%$ and $92.70 \%$ for the $2^{\text {nd }}, 3^{\text {rd }}$ and $4^{\text {th }}$ months respectively. An observable polynomial trend line was also used to describe the fluctuations of WSG monthly performance data set, and provide visualization on the relationship of the WSG monthly performance versus the monthly SLA.

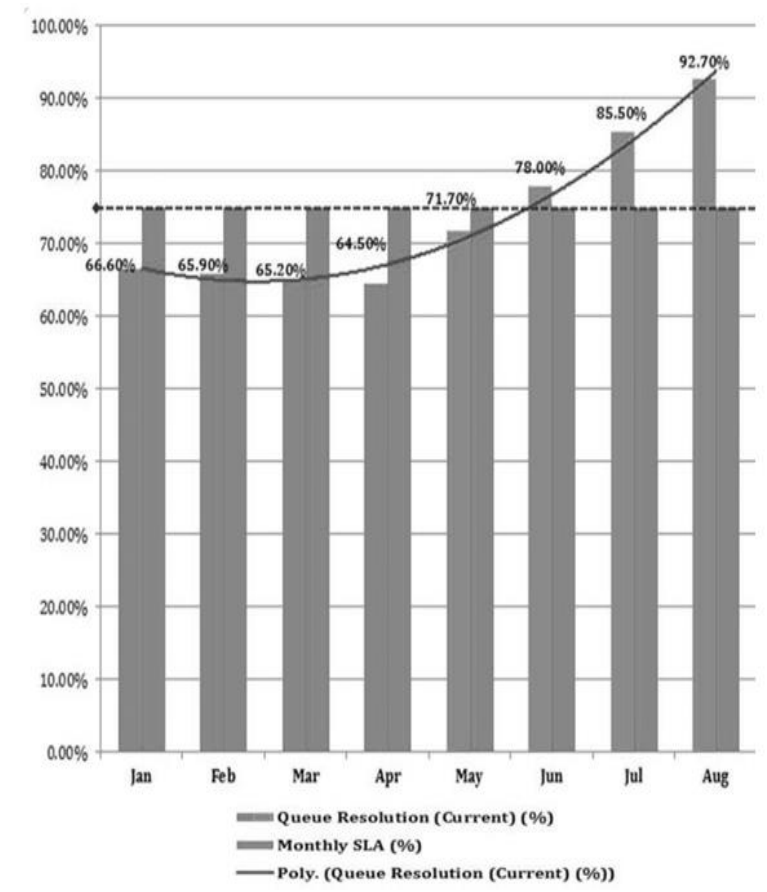

FIGURE 13. Monthly WSG performance during the pre and post Kaizen project implementation

In terms of the SWG weekly MTTR, Figure 15 describes how the process improvement contributed to the significant drop of the AHT in minutes. A week after the post implementation, there was a significant drop in the $1^{\text {st }}$ week of May; WSG AHT was $80.67 \%$ and ended at $42.56 \%$ during the last week of May.

This improvement in the AHT brought an impact on its monthly percentage of resolution which was $71.70 \%$ with $7.2 \%$ higher than the April percentage of fallout resolution. Notwithstanding, percentage of resolution for May, June July and August were very optimistic as 15 min AHT was achieved during the $1^{\text {st }}$ week of the $4^{\text {th }}$ month or $16^{\text {th }}$ week of the post project implementation. For the time being, WSG weekly AHT entitlement was 10 minutes.

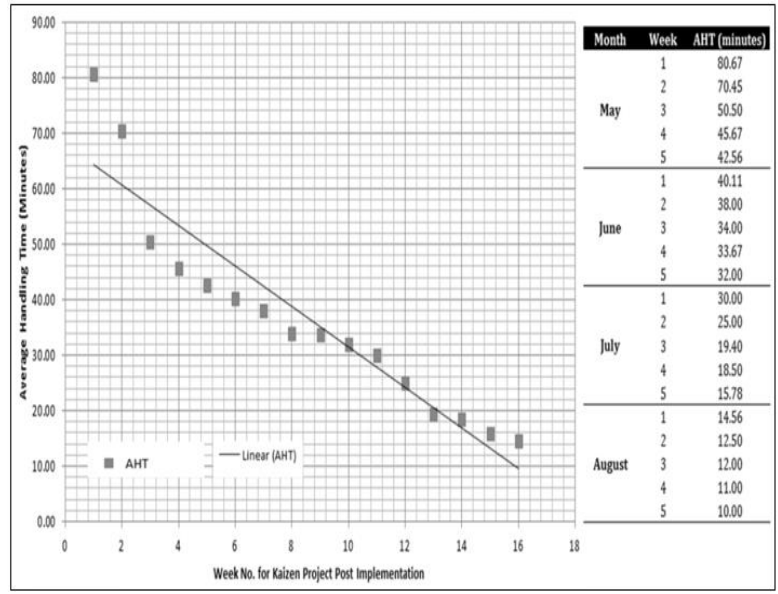

FIGURE 14. Weekly WSG MTTR on post Kaizen project implementation

\section{Process Capability}

Measuring and reporting the organizational and operational performance are usually at a sigma level. A processcentric and service-oriented organization always aims to achieved higher sigma level because the higher the sigma level that organization has, the better its performance. Another way of performance reporting is by way of process capability through the statistical measurements of Process Capability (Cp), Process Capability Index (Cpk), Process Performance (Pp) and Process Performance Index (Ppk). The process capability index ( $\mathrm{Cpk}$ ) has long been used in several industries in the sectors of the economy to provide numerical measures of process potential and performance Pearn (1998) and determine whether the process is capable of producing the requirements of the specified item within the item specifications and tolerance (Parchami, Mashinchi \& Maleki, 2006). In order to satisfy the customers' needs, or provide a quality service, a process must have a capability index greater than or equal to 1.33 or better which is attributed to be at 4 sigma level or $99.38 \%$ yield. Process capability index is used in short term plans and Process Performance for the long term scheme if the process can withstand variations of technology upgrades, customers' demands and other factors in the service industry. In this project, the variations were considered to bring impact on the end-users and service provisioning and in effect will challenge the ability of the process, hence the Process Capability Index (Cpk) was used as the measure. In Figure 16, the Process Capability Summary 
and Process Capability Index (Cpk) Moving Range Average it shows that the potential Process Capability Index is 1.59 which is higher or better than 1.33 . This Cpk measure im- plies that the improvement process can deliver and satisfy the services supported by the WSG.

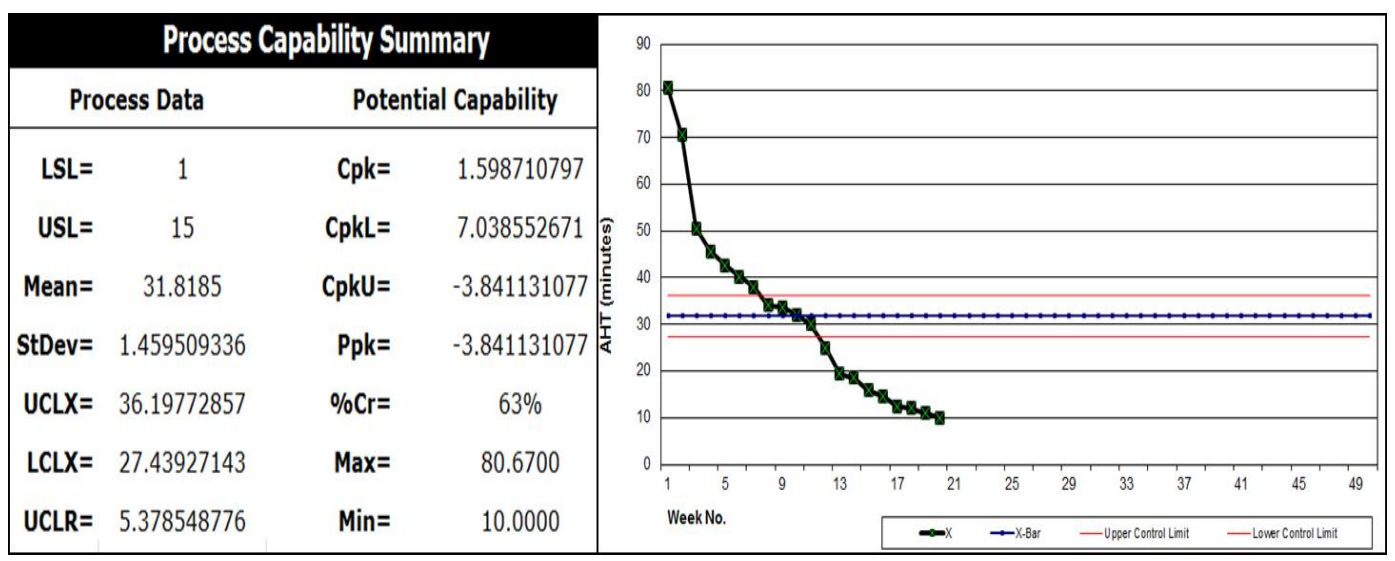

FIGURE 15. The process capability summary and Process Capability Index (Cpk) moving range average

\section{Control Phase: OCAP, Control Charts and Dashboard}

In the Lean Six Sigma DMAIC model, the Control Phase is the last phase. During this phase, process improvement and other initiatives integrated into the WSG group must be looked into. The focus of this phase is to cross-check on the implementation of the implied changes, documentation, assessment and evaluation of the project impact and develops courses of action to sustain the improvement. Various tools can be used in this phase such as Out-of-control Plan and Control Charts. An out of control action plan is used to provide the detailed guidelines for process adjustment with the required changes in the process Little (2001), Schippers (2001) during out of control. A control chart is a graphical tool used to track and visualize how the process changes for a period. It presents a central line, upper limit and lower control limit determined based on the data.

\section{OCAP, and Control Charts}

There have been appropriate documentation and knowledge transition sessions being conducted to acquaint the process owners with the process documents and how to go about in the production. Despite of the stringent implementation and process monitoring, organizations slip back; a control plan which documents the quality elements in order that the service is delivered and met.

The Control Plan contains the process item, process review, frequency of review, measures and verifiable elements of service quality in performing the corrective and perfective actions. To ensure that the value of the service and its quality are put on customers first, an OCAP with Reaction Plan has been designed. The OCAP with Reaction Plan is an embedded flowchart which provides guidance and process action items when there is an out-of-control situation. Figure 16 shows a Reaction Plan for Control Plan for Critical Process: WA for Fallout Resolution with a Critical to Quality Issue: Applied to Incidents and Problem Resolution.

TABLE 4. Control chart data

\begin{tabular}{lll}
\hline \hline 31.819 Xbar/IMR chart avg & 35.12 Xbar one sigma uppar limit & 6.534 Rbar one sigma uppar limit \\
3.7195 rang chart avg & 38.41 Xbar two sigma uppar limit & 9.348 Rbar two sigma uppar limit \\
3.297406 Rbar/d $\mathrm{d}_{2}$ & 41.71 Xbar three sigma uppar limit & 12.16 Rbar three sigma uppar limit \\
20 number of samples & 28.52 Xbar one sigma lower limit & 0.905 Rbar one sigma lower limit \\
1 subgroup size & 25.22 Xbar two sigma lower limit & n/a Rbar two sigma lower limit \\
20 number of subgroups & 21.93 Xbar three sigma lower limit & n/a Rbar three sigma lower limit \\
\hline \hline
\end{tabular}


Individuals Chart

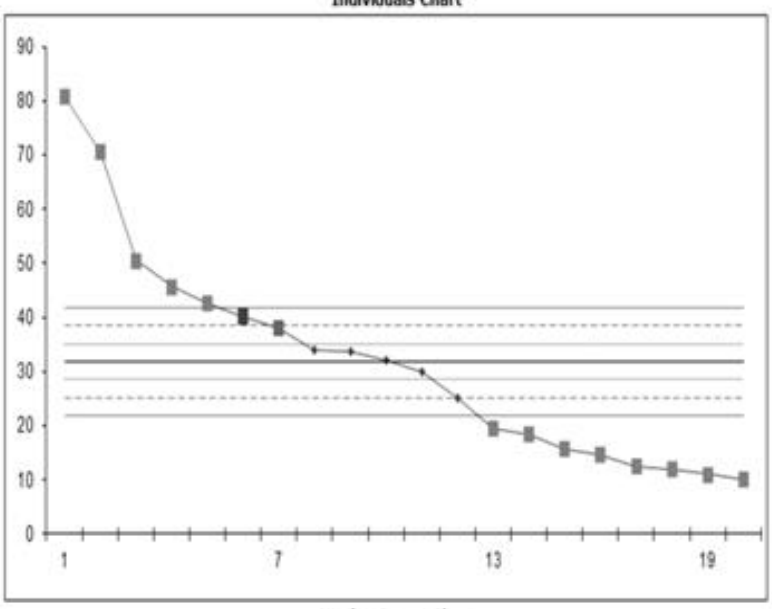

Moving Range Chart

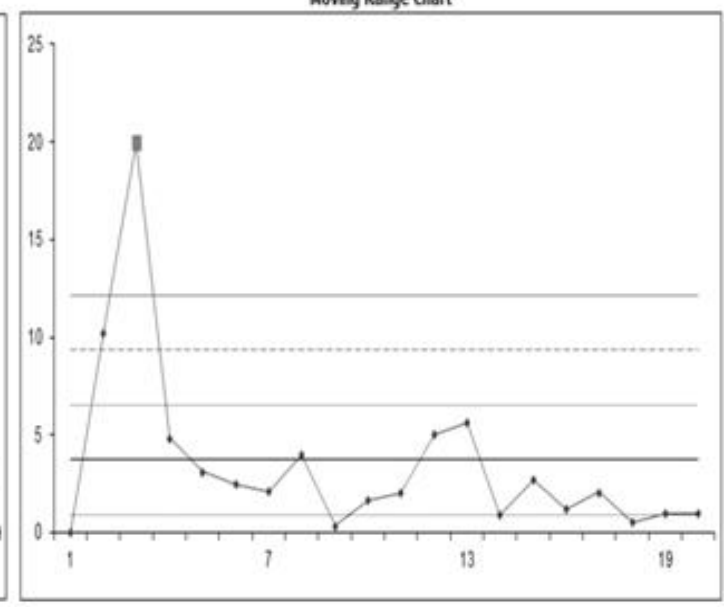

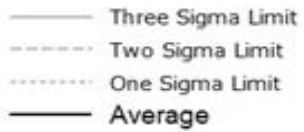

Average

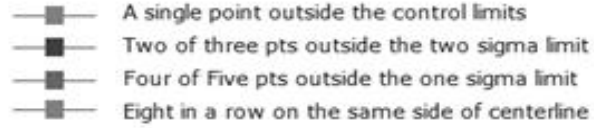

Eight in a row on the same side of centerline

FIGURE 16. A reaction plan for control plan for critical process: WA for fallout resolution

A Control Chart is used to countervail process change output behavior and examine if the process can withstand over time. It is used in process improvement endeavors to describe process attributes and characteristics, process inspection Page (1955), assess and evaluate various methods and even monitoring and control processes (Liu, 1995). Figure 16 shows that $X$-Bar and $R$-Chart were used to describe the process behaviour of the continuous data and charted with the Individual and Moving Range to illustrate a geometric distribution Kaminsky, Benneyan, Davis \& Burke (1992) of change over time. The Individual Chart describes the Mean ( $X$-Bar) of the WSG MTTR fallout issues with $31.819 \mathrm{Xbar} / \mathrm{IMR}$ Chart Average. The Moving Range Chart presents the range between the weeks of WSG MTTR with a Range Chart Average of 3.7195. Based on the charts, variability on MTTR was reduced overtime.

\section{Design and Development of Dashboard for WSG}

A web-based dashboard has been developed to provide real-time operational and business data analytics for WSG and Service Support Group. The dashboard purposely devised to serve as visualization tool on the actual figures versus the targets, summarized and detailed total number of fallout issues, the number of incidents, and the number of problems and defects in the queue management system. It also presents the real-time status of the fallout with the total number of assigned, unassigned, aging and undergoing resolution (on-progress). In terms of the WSG performance and resolutions, the dashboard displays the percentage of resolved fallout, standing MTTR (daily, weekly, monthly and quarterly) for the time being, and its SLA Level and Key Performance Indicators. The dashboard is composed of scatter diagram, histogram, bar chart and pie-chart. The pie-chart provides the $\%$ contribution of each WSG analyst to the total resolved fallout of the group. Dashboard is a powerful tool in managing team performance and prioritizing strategic data of the organization. The dashboard provides an analytical report from the service data, information related to the service in visual format, an automated and scheduled WSG reporting management with Comma Separated values (CSV), pdf, scheduled back-up and email to WSG distribution list and other functions.

\section{CONCLUSION AND RECOMMENDATIONS}

This study intended to provide a comprehensive walkthrough on the Kaizen project implemented in an organization with the overarching process innovation in the processes and even in the technology to improve performance. The project pegged to devise a functional process innovation, employ Lean Six Sigma as business process improvement methodologies, develop a one-time service fallout resolution scheme, and streamlined the queue management 
process to improve the department's average, meet and exceed the SLA further. The results show that the Kaizen Project positively impacted the WSG productivity and support efficiency. With the process innovation, a one-time resolution scheme, the queue management was streamlined. The Kaizen Project has raised and improved the WSG fallout resolution performance and even exceeded the 75\% SLA with the customer. The Lean thinking and lean six sigma process improvement initiative have had improved WSG monthly AHT and even exceed the agreed 15 min AHT since the WSG entitlement is at 10 minutes within the 4th month of post project implementation. The researcher recom- mends that the WSG will continuously embark on process improvement to continuously improve the performance, document lessons learned and share the best practices in the Kaizen project. Also, it is important that the organization shall champion LSS on a larger scale and support operational units in institutionalizing the same undertaking. Further studies could be done on the basis of how one-time scheme process can better the quality of the service or product such as using the cycle time accounting and other process improvement methodology.

\section{REFERENCES}

Abdullah, R., Selamat, M.H., Sahibudin, S., \& Alias, R.A. 2005. A framework for knowledge management system implementa- tion in collaborative environment for higher learning institution. Journal of Knowledge Management Practice, 6(1): $\quad 1-10$. Adams, M., Componation, P. , Czarnecki, H., \& Schroer, B.J. 1999. Simulation as a tool for continuous process improvement. Paper presented in Simulation Conference Proceedings, Phoenix, AZ, 1999.

Andersen, B. 2007. Business process improvement toolbox. Milwaukee, WI: ASQ Quality Press.

Antony, J. 2004. Some pros and cons of six sigma: An academic perspective. The TQM Magazine, 16(4): 303-306.

DOI: $10.1108 / 09544780410541945$

Antony, J., \& Banuelas, R. 2002. Key ingredients for the effective implementation of Six Sigma program. Measuring Business Excellence, 6(4): 20-27. DOI: 10.1108/13683040210451679

Antony, J., Krishan, N., Cullen, D., \& Kumar, M. 2012. Lean Six Sigma for Higher Education Institutions (HEIs) challenges, barriers, success factors, tools/techniques. International Journal of Productivity and Performance Management, 61(8): 940-948. DOI: 10.1108/17410401211277165

Atallah, Z.B., \& Ramudhin, A. 2010. Improving healthcare reliability by integrating Six-sigma in a business process modeling and analysis strategy. Paper presented in IEEE International Conference on Industrial Engineering and

En- gineering Management, Macao, China.

Athuraliya, S., Low, S.H., Li, V.H., \& Yin, Q. 2001. REM: Active queue management. IEEE Network, 15(3): 48-53.

DOI: $10.1109 / 65.923940$

Ayuningrat, M.P., Noermijati., \& Hadiwidjojo, D. 2016. Green product innovation's effect on firm performance of managerial environmental concern and green communication. Journal of Administrative and Business Studies, 2(2): 56-63. DOI: $10.20474 /$ jabs-2.2.1

Barber, K.H., Schultz, K., Scott, A., Pollock, E., Kotecha, J., \& Martin, D. 2015. Teaching quality improvement in graduate medical education: An experiential and team-based approach to the acquisition of quality improvement competencies. Academic Medicine, 90(10): 1363-1367. D0I: 10.1097/acm.0000000000000851

Bartolini, C., Sallé, M., \& Trastour, D. 2006. IT service management driven by business objectives An application to inci- dent management. Paper presented in $10^{\text {th }}$ IEEE/IFIP Conference on Network Operations and Management Symposium, Vancouver, Canada, 2006.

Bicheno, J. 1998. The quality 60: A guide for service and manufacturing. Buckingham, UK: Picsie Books.

Bornemann-Shepherd, M., Le-Lazar, J., Makic, M.B.F., DeVine, D., McDevitt, K., \& Paul, M. 2015. Caring for inpatient board- ers in the emergency department: improving safety and patient and staff satisfaction. Journal of Emergency Nursing, 41(1): 23-29. DOI: 10.1016/j.jen.2014.04.012

Brenner, M. 2006. Classifying ITIL processes: A taxonomy under tool support aspects. Paper presented in First IEEE/IFIP International Workshop on Business-Driven IT Management, Vancouver, Canada, 2006.

Brewer, P. C., \& Bagranoff, N.A. 2004. Near zero-defect accounting with Six Sigma. Journal of Corporate Accountina \& ISSN: 2414-309X 
Finance, 15(2): 67-72. DOI: 10.1002/jcaf.10235

Byrne, G., Lubowe, D., \& Blitz, A. 2007. Using a Lean Six Sigma approach to drive innovation. Strategy \& Leadership, 35(2): 5-10. DOI: /10.1108/10878570710734480

Chait, L.P. 1999. Creating a successful knowledge management system. Journal of Business Strategy, 20(2): 23-26.

DOI: $10.1108 / \mathrm{eb} 039991$

Chang, J.I., \& Lin, C.C. 2006. A study of storage tank accidents. Journal of Loss Prevention in the Process Industries, 19(1):

51-59. DOI: 10.1016/j.jlp.2005.05.015

Chiarini, A. 2012. From total quality control to lean six sigma. New Yo rk, NY: Springer.

Cole, R.A., Goldberg, L.G., \& White, L.J. 2004. Cookie cutter vs. character: The micro structure of small business lending by large and small banks. Journal of Financial and Quantitative Analysis, 39(2): 227-251.

DOI: $10.1017 / \mathrm{s} 0022109000003057$

Copperman, M., Angel, M., Rudy, J.H., Huffman, S.B., Kay, D.B., \& Fratkina, R. 2004. U.S. patent no. 6,711,585. Washington, DC, WA: U.S. Patent and Trademark Office.

Dasig Jr, D.D. 2014. A Study on the sectors of economy serviced by pre-industry system developers among companies in metro Manila: A tool for business reengineering. International Journal of Business Information Systems Strategies, 3(3): 1-15. DOI: 10.14810/ijbiss.2014.3301

Dasig Jr, D.D., \& Gatpandan, M.P. 2013. Change management of transitioned Information System (IS) to Management Information System (MIS) of the course system analysis and design 1 \& 2 of Jose Rizal university: A basis for a comp- rehensive policies redirection. Paper presented 10ème Session Du Congrès International Sur La Qualité De L'Education Et De La Formation, Marrakech, Morocco.

Dasig Jr., D., Valderama, A.M., Gatpandan, M., Taduyo, M.A.B., Traballo, R., Pangan, S., \& Gatpandan, P. 2014. Fishbone analy- $\quad$ sis on wastes in software development using the lean IT principles. Electrical \& Computer Engineering: An Interna- tional Journal , 3(4): 31-44. DOI: 10.14810/ecij.2014.3403

Davenport, T.H., \& Short, J.E. 1990. The new industrial engineering: information technology and business process redesign.

Sloan Management Review, 31(4): 11-27.

Desai, T. N., \& Shrivastava, R.L. 2008. Six Sigma-a new direction to quality and productivity management. Paper pre- sented in Proceedings of the World Congress on Engineering and Computer Science, San Farnsico, CA.

Eiden, C., Peyrière, H., Cociglio, M., Djezzar, S., Hansel, S., Blayac, J.P. , \& Hillaire-Buys, D. 2007. Adverse effects of voriconazole: $\quad$ Analysis of the French Pharmacovigilance Database. Annals of Pharmacotherapy, 41(5): 755-763.

DOI: $10.1345 / \mathrm{aph} .1 \mathrm{~h} 671$

Frakes, W.B., \& Fox, C.J. 1996. Quality improvement using a software reuse failure modes model. IEEE Transactions on Software Engineering, 22(4): 274-279. DOI: 10.1109/32.491652

Furterer, S., \& Elshennawy, A.K. 2005. Implementation of TQM and lean Six Sigma tools in local government: A framework and a case study. Total Quality Management \& Business Excellence, 16(10): 1179-1191.

DOI: $10.1080 / 14783360500236379$

George, M.L., \& George, M. 2003. Lean six sigma for service. New Yo rk, NY: McGraw-Hill.

Goetsch, D.L., \& Davis, S. 1994. Introduction to total quality: Quality, productivity, competitiveness. Basingstoke, UK: Macmillan Publishers.

Gronroos, C. 1990. Service management: A management focus for service competition. International Journal of Service Industry Management, 1(1): 6-14. DOI: 10.1108/09564239010139125

Grönroos, C. 1994. From scientific management to service management: A management perspective for the age of service competition. International Journal of Service Industry Management, 5(1): 5-20. DOI: 10.1108/09564239410051885 Guha, S., Kettinger, W. J., \& Teng, J.T. 1993. Business process reengineering: Building a comprehensive methodology. Infor- mation Systems Management, 10(3): 13-22. DOI: 10.1080/10580539308906939

Gummesson, E. 1994. Service management: An evaluation and the future. International Journal of Service Industry Man- agement, 5(1): 77-96. DOI: 10.1108/09564239410051920 
tional Conference on Autonomic Computing, Chicago, IL.

Gupta, R., Prasad, K.H., Luan, L., Rosu, D., \& Ward, C. 2009. Multi-dimensional knowledge integration for efficient incident management in a services cloud. Paper presented in International Conference on Services Computing, Bangalore,

India.

Harry, M.J. 1998. Six sigma: A breakthrough strategy for profitability. Quality Progress, 31(5): 60-64.

DOI: 10.1515 /eqc.2005.171

Harry, M.J., \& Schroeder, R.R. 2005. Six sigma: The breakthrough management strategy revolutionizing the world's top corporations. Danvers, MA: The Crown Publishing Group.

Havens, C.T. 1999. U.S. patent no. 5,924,072. Washington, DC, WA: U.S. Patent and Trademark Office.

He, Q., Yan, J., Kowalczyk, R., Jin, H., \& Yang, Y. 2009. Lifetime service level agreement management with autonomous agents for services provision. Information Sciences, 179(15): 2591-2605. DOI: 10.1016/j.ins.2009.01.037

Ishikawa, K., \& Lu, D.J. 1985. What is total control the Japanese way. Englewood Cliffs, NJ: Prentice Hall.

Jain, S., \& McLean, C.R. 2005. Integrated simulation and gaming architecture for incident management training. Paper presented in Proceedings of the Winter on Simulation Conference, Lake Buena Vista, FL.

Jakobsson, M., \& Rosenberg, N.A. 2007. Clumpp: A cluster matching and permutation program for dealing with label switchand multimodality in analysis of population structure. Bioinformatics, 23(14): 1801-1806.

DOI: $10.1093 /$ bioinformatics/btm233

Johnson, R.A., Miller, I., \& Freund, J. 2000. Probability and statistics for engineers. URL: goo.gl/F86kNt. Last accessed on 21 December 2017.

Kaminsky, F.C., Benneyan, J.C., Davis, R.D., \& Burke, R.J. 1992. Statistical control charts based on a geometric distribution. Journal of Quality Technology, 24(2): 63-69.

Kellogg, D.L., \& Nie, W. 1995. A framework for strategic service management. Journal of Operations Management, 13(4): 323-337. DOI: 10.1016/0272-6963(95)00036-4

Kuo, M.P., \& Chen, Y.M. 2015. A Study on the relationships among body sensory experience, customer satisfaction and cus- $\quad$ tomer loyalty-beauty SPA center as an example. International Journal of Business and Administrative Studies, 1(2): $\quad$ 61-67. DOI: 10.20469/ijbas.10003-2

Kwak, Y.H., \& Anbari, F. T. 2006. Benefits, obstacles, and future of six sigma approach. Technovation, 26(5): 708-715.

DOI: $10.1016 /$ j.technovation.2004.10.003

Lee, S.M., \& Hong, S. 2002. An enterprise-wide knowledge management system infrastructure. Industrial Management \& Data Systems, 102(1): 17-25. DOI: 10.1108/02635570210414622

Linderman, K., Schroeder, R.G., Zaheer, S., \& Choo, A.S. 2003. Six Sigma: A goal-theoretic perspective. Journal of Operations

Management, 21(2): 193-203. DOI: 10.1016/s0272-6963(02)00087-6

Little, T.A. 2001. 10 requirements for effective process control: A case study. Quality Progress, 34(2): 46-52.

Liu, R.Y. 1995. Control charts for multivariate processes. Journal of the American Statistical Association, 90(432): 1380-

DOI: $10.2307 / 2291529$

Mumford, D. 1994. Elastica and computer vision. In C. L. Bajaj (Eds.), Algebraic geometry and its applications. New York,

NY: Springer.

Page, E.S. 1955. Control charts with warning lines. Biometrika, 42(1-2): 243-257. DOI: 10.2307/2333440

Pande, P.S., Neuman, R.P., \& Cavanagh, R.R. 2000. The six sigma way. New Yo rk, NY: McGraw-Hill.

Parchami, A., Mashinchi, M., \& Maleki, H.R. 2006. Fuzzy confidence interval for fuzzy process capability index. Journal of Intelligent \& Fuzzy Systems, 17(3): 287-295.

Pearn, W. L. 1998. New generalization of process capability index Cpk. Journal of Applied Statistics, 25(6): 801-810.

DOI: $10.1080 / 02664769822783$

Psychogios, A.G., \& Priporas, C.V. 2007. Understanding total quality management in context: Qualitative research on manawareness of TQM aspects in the Greek service industry. The Qualitative Report, 12(1): 40-66.

DOI: $10.1108 / 09544780710720844$

Robson, G.D. 2010. Continuous process improvement. New York, NY: Simon and Schuster. 
Rossi, M., Taisch, M., \& Te rzi, S. 2012. Lean product development: A five-steps methodology for continuous improve- $\quad$ ment. Paper presented in $8^{\text {th }}$ International ICE Conference on Engineering, Technology and Innovation, Munich, Ger- many.

Ramanan, L., Kumar, M., \& Ramanakumar, K.P. V. 2014. Six sigma-DMAIC frame work for enhancing quality in engineering educational institutions. International Journal of Business Management Invention, 3(1): 36-40.

Rummler, G.A., \& Brache, A.P. 2012. Improving performance: How to manage the white space on the organization chart. San Francisco, CA: John Wiley \& Sons.

Saraiva, P. M., \& Stephanopoulos, G. 1992. Continuous process improvement through inductive and analogical learning. Aiche Journal, 38(2): 161-183. D0I: 10.1002/aic.690380202

Schippers, W.A. 2001. An integrated approach to process control. International Journal of Production Economics, 69(1): 93-105. DOI: 10.1016/s0925-5273(98)00243-6

Shtub, A., \& Karni, R. 2010. Business process improvement. In A. Shtub \& R. Karni (Eds.), ERP: The dynamics of supply chain and process management. New York, NY: Springer.

Sokovic, M., Pavletic, D., \& Fakin, S. 2005. Application of six sigma methodology for process design. Journal of Materials Processing Technology, 162: 777-783. D0I: 10.1016/j.jmatprotec.2005.02.231

Ward, J.A. 1994. Continuous process improvement. Information System Management, 11(2): 74-76. DOI: $10.1080 / 10580539408964640$

Wilkinson, L. 2006. Revising the pareto chart. The American Statistician, 60(4): 332-334.

DOI: $10.1198 / 000313006 \times 152243$

Yang, K., \& El-Haik, B.S. 2003. Design for six sigma. New York, NY: McGraw-Hill.

Zurich, L.B. 2017. Service operations and management. URL: goo.gl/ucgbQr. Last accessed on 1 July 2017.

- This article does not have any appendix. - 